\title{
LA CUEVA DE LOS MURCIÉLAGOS DE ZUHEROS (CÓRDOBA): HÁBITAT Y SANTUARIO DURANTE EL NEOLÍTICO ANTIGUO. HOGARES, PAPAVER SOMNIFERUM Y SIMBOLISMO
}

\author{
THE CAVE OF LOS MURCIÉLAGOS AT ZUHEROS (CÓRDOBA): HABITAT AND SANCTUARY \\ DURING THE EARLY NEOLITHIC. HEARTHS, PAPAVER SOMNIFERUM AND SYMBOLISM
}

\author{
B. GAVILÁN CEBALLOS * \\ M. MAS CORNELLÁ **
}

\begin{abstract}
Resumen: Presentamos en este trabajo una serie de restos recuperados en un hogar, excavado en la campaña de 1991, encendido en uno de los niveles iniciales del Neolítico Antiguo de la Cueva de los Murciélagos de Zuheros. Las características del hogar, la peculiaridad de los ecofactos que ha proporcionado y la presencia de manifestaciones artísticas en el mismo sector de la cavidad donde se efectuó la excavación, junto con algunas cerámicas simbólicas, nos permiten plantear que los primeros productores establecidos en esta cavidad llevaron a cabo unas actividades que relacionamos con la práctica de algún tipo de ritual.

Palabras clave: Neolítico, Hogares, Cerámicas Simbólicas, Manifestaciones artísticas, Papaver somniferum, Ídolos, Ritual.
\end{abstract}

\section{INTRODUCCIÓN}

Desde 1990 hasta 2002 hemos venido realizando nuevos trabajos en el interior de la Cueva de los Murciélagos de Zuheros consistentes en la excavación de la zona denominada "Pasillo" o "Paso del Jubilado", uno de los escasos sectores que aún cuenta con sedimento

* Área de Prehistoria. Dpto. de Historia 1. Facultad de Humanidades. Universidad de Huelva. Avda. Fuerzas Armadas, S/N. Huelva. beatriz.gavilan@dhis1.uhu.es.959-219086,650-737317.

**Área de Prehistoria. Dpto. de Prehistoria e Historia Antigua. U.N.E.D. $\mathrm{P}^{\circ}$. Senda del Rey, ${ }^{\circ}$ 7, 28040 Madrid.

\begin{abstract}
We present,in this study, a series of artefects recovered from the remains a fire that was found in one of the levels of the Early Neolithic period during an excavation carried out in 1991 in the Cueva de los Murciélagos, Zuheros. The characteristics of the fire, together with the ecofacts, artistic manifestations and symbolic ceramics found near to the fire suggests that the first inhabitants of this cave carried out activities that could be related to some type of ritual.

Keywords: Neolithic, Fires, Symbolic Ceramics, Artistic Manifestations, Papaver somniferum, Idols, Ritual.
\end{abstract}

arqueológico, y en la documentación exhaustiva de las manifestaciones artísticas que la cueva alberga en su interior. Estos trabajos han proporcionado una gran cantidad de datos referentes a economía, clima y vegetación, estructuras -de combustión, almacenamiento, escalones y agujeros para poste-, fechas de $\mathrm{C}-14 \mathrm{y}$, entre otros, un volumen más que considerable de restos materiales a lo largo de una potente estratigrafía que parte de los momentos plenos del Paleolítico Medio, algunos niveles correspondientes a finales del Paleolítico Superior, Neolítico, período ampliamente representado, Calcolítico y Edad de los Metales, finalizando con unos niveles de época romana tardía. 
En el presente trabajo planteamos la posible relación existente entre determinados restos cerámicos, carpológicos, hogares neolíticos y algunas manifestaciones artísticas postpaleolíticas como partes integrantes de un ritual.

\section{TRABAJOS DE EXCAVACIÓN}

La Cueva de los Murciélagos de Zuheros se encuentra en la vertiente $\mathrm{N}$ del Macizo de Cabra, perteneciente a las Sierras Subbéticas cordobesas, en el SE de la provincia de Córdoba. Esta cueva ha sido objeto en 1990, 1991, 1993 y 2002 de nuevos trabajos arqueológicos, dirigidos por uno de los firmantes, que se han practicado en el "Pasillo" o "Paso del Jubilado" (Fig. 1), en la Cueva Grande, situado a continuación del "Vestíbulo" y a escasos metros del "Corredor de las Pinturas" y de la "Rampa", que albergan la mayor parte de las manifestaciones artísticas. Salvo un ancoriforme y varias manchas que se localizan en el "Panel de las Cabras", un cuadrúpedo muy esquematizado plasmado igualmente en el "Corredor de las Pinturas", aunque en otro panel, y los antropomorfos de brazos en asa, ubicados en la "Sala de los Estratos" de la Cueva Chica, para los que se empleó el rojo, el resto de las manifestaciones se pintaron con carbón.

Como hemos expuesto en anteriores trabajos (Gavilán 1991; Gavilán et alii 1994; Gavilán et alii 1996), la metodología empleada ha consistido, en todas las campañas, en la excavación por niveles naturales, diferenciados por su color, textura y composición. El 100\% del sedimento de cada U.S. fue sometido a flotación, mediante el sistema de tanque, empleándose dos tipos de malla, una doble de $1 \mathrm{~mm}$ de luz para el sedimento, y otra de 0’25 mm para la recogida de las flotaciones. Gracias a ello pudieron recuperarse gran cantidad de microfauna, restos de carbones, semillas y artefactos (fragmentos de elementos ornamentales, restos de talla, entre otros, que por su reducido tamaño no resultan visibles durante el proceso de excavación dado el grado de humedad y el carácter arcilloso del sedimento).

Sin duda, esta cavidad ha constituido, desafortunadamente a nuestro juicio, el exponente del Neolítico Medio andaluz por la ausencia de cerámicas impresas cardiales y la abundancia de decoraciones a la almagra. Murciélagos de Zuheros como equivalente de la citada fase partió de los resultados de las excavaciones efectuadas por Vicent y Muñoz en 1969 (1973), y fue convirtiéndose en dogma a medida que se daban a conocer más yacimientos neolíticos andaluces, cuyas secuencias se equiparaban invariablemente con las de la orla levantina y la obtenida en la Cueva de la Carihuela, esta última paradigma del horizonte cardial en Andalucía.
En contra de la adjudicación a la fase media nos hemos pronunciado, con argumentos de peso, en repetidas ocasiones (Gavilán 1997; Gavilán y Vera 2001), indicando, tanto por las fechas de C-14 obtenidas como por su cultura material, que la mayor parte de la ocupación correspondiente a las primeras sociedades productoras representa al Neolítico Antiguo, no cardial, en Andalucía, adjudicación plenamente aceptada ya por diferentes investigadores (Bernabeu et alii 1999) en cuyas zonas de actuación la cardial es la primera cerámica que se documenta. Si bien, no es menos cierto que este Neolítico Antiguo que defendemos se considera, en función de la secuencia levantina, como epicardial -antiguo, medio y reciente- ante la ausencia de las decoraciones impresas cardiales (Ibidem).

La secuencia neolítica obtenida a lo largo de las excavaciones, más de 70 UU.SS., la hemos dividido en tres bloques: A, B y C, basándonos para ello en la evolución del material cerámico, que en ningún momento hemos pretendido asimilar a la tradicional división tripartita del Neolítico (Gavilán et alii 1996; Gavilán y Vera 2001). Estos bloques se han visto corroborados por las fechas de C-14 proporcionadas por el laboratorio Teledyne Isotopes (New Jersey, USA). El primero de ellos se sitúa entre el $4.480 \pm 130$ y el $3.950 \pm 120$ a.C. (I-17.772 e I-17.775, carbón), como fechas más antigua y más reciente, remontándose a la segunda mitad del VI milenio y primer tercio del V en fechas calibradas. El Neolítico B, queda comprendido entre el 3.850 \pm 120 y el $3.620 \pm 110$ a.C. (I-17.770 e I-17.764, carbón), es decir, el segundo tercio del V milenio cal. a.C. Finalmente, los niveles del Neolítico $\mathrm{C}$ han arrojado unas fechas entre el $3.430 \pm 110$ y el $3.130 \pm 120$ a.C. (I-17.762 e I-17.761), finales del V y comienzo del IV milenios cal. a.C.

Estamos, pues, cronológicamente ante un Neolítico Antiguo no cardial, sobre todo en lo referente a los niveles que integran los bloques $\mathrm{A}$ y $\mathrm{B}$, siendo el primero de ellos el que precisamente nos interesa en este trabajo.

Este bloque, que abarca desde la U.S. 41 a la 83, según la campaña de 1993 (Gavilán et alii 1996), se caracteriza por la abundancia de cerámicas decoradas que corroboran la adjudicación al Neolítico Antiguo, sobresaliendo los grandes recipientes de cerámica a la almagra, de calidad excepcional y con diversas asociaciones decorativas; son frecuentes las cerámicas con aplicación de cordones, las incisas con variados motivos, así como las impresas basculantes y a peine, que cuentan con una buena representación. En cuanto a la industria lítica tallada destaca el pequeño formato de los productos y la presencia de elementos de hoz con pátina de siega (Ibáñez y González 1996; González et alii 2000), 
como útiles más significativos; por su parte, el conjunto industrial óseo lo integran fundamentalmente punzones, y el ornamental brazaletes de concha y mármol, cuentas de collar y colgantes. A este bloque pertenecen los hogares detectados en las campañas de 1991, 1993 y 2002, sobre los que incidiremos más adelante.

Si bien es el bloque que ha proporcionado los restos más importantes para el trabajo que ahora nos ocupa, no queremos dejar de señalar la existencia de otras estructuras, localizadas en los bloques B y C (Gavilán et alii 1996; Vera y Gavilán 1999). A techo de los niveles correspondientes Neolítico $\mathrm{C}$-bloque $\mathrm{C}$-, documentamos una serie de depresiones, de $30 \mathrm{~cm}$ de longitud por $40 \mathrm{~cm}$ de anchura, excavadas en el talud que recorrían la zona diagonalmente, de $\mathrm{E}$ a O, es decir, partían del final del "Vestíbulo" en dirección a la "Rampa"; presentan claras improntas de vegetales y señales de pisoteo, y las hemos interpretado como escalones para facilitar el paso por el talud. La fecha a partir de la cual se excavan estas estructuras viene dada por las dataciones absolutas obtenidas para este bloque $\mathrm{C}$, indicadas más arriba; al Neolítico B corresponden tres fosas que hemos interpretado como destinadas a almacenamiento indirecto, sus medidas oscilan entre $60-70 \mathrm{~cm}$ de diámetro medio y 40-50 cm de profundidad, y se excavaron en la misma unidad sedimentaria. La fecha obtenida en el nivel inmediatamente infrapuesto, $3.850 \pm 120$ a. C. (I-17.770, carbón), permite datar el momento a partir del cual se construyeron (Vera y Gavilán 1999).

Los nuevos trabajos de investigación en el interior de la cavidad hubiesen quedado incompletos de no haberse abordado paralelamente un análisis exhaustivo de las manifestaciones artísticas existentes. Ciertamente, aunque ya desde mediados de los años 40 hay noticias (Carbonell 1945; Mata Funes 1946) acerca de la existencia de Arte Esquemático Postpaleolítico (A.E.P., en adelante) en este yacimiento, el trabajo más completo, debido a Bernier y Fortea, databa de finales de los sesenta (1968-69), siendo necesario, por tanto, una revisión, puesto que muchas de las manifestaciones publicadas pasaron desapercibidas en posteriores trabajos arqueológicos, quedando en el olvido su exacta ubicación. Este es el caso, por ejemplo, de los antropomorfos de brazos en asa dados a conocer por Carbonell (1945), que, situados en una de las paredes de la "Sala de los Estratos" de la Cueva Chica, pasaron inadvertidos durante las excavaciones de 1969, o de algunos "ídolos" publicados por Bernier y Fortea, cercanos al "Panel de las Cabras". Dicho panel se convirtió en el exponente del A.E.P. de la Cueva de los Murciélagos de Zuheros, bien por el desarrollo de la cornamenta de cuatro de estos cápridos, bien por la cuestión, siempre interesante sin duda, de su adscripción cultural, que del Bronce I hispano, propuesto por Bernier y Fortea (1968-69), muy en consonancia con la fecha de publicación, pasó a adjudicarse al Neolítico (Marcos Pous 1977) tras los resultados de las excavaciones realizadas en la "Sala de los Estratos" de la Cueva Chica. Sin embargo, revisando los datos publicados por Bernier y Fortea (196869) quedaba más que claro que existían otras manifestaciones en las paredes de la cueva, algunas de ellas poco usuales dentro del A.E.P., como determinados motivos y temas en negro.

Así, pues, este nuevo estudio tenía como objetivos una revisión y una documentación rigurosa de las manifestaciones artísticas que alberga la cavidad, llevándonos esto al "redescubrimiento" de motivos hace tiempo olvidados, entre los que destacamos los antropomorofos de brazos en asa, en rojo, y los "ídolos", constituyendo éstos últimos, junto con varios hogares y determinados restos, procedentes tanto de superficie como de excavación, la base del presente trabajo.

Como hemos señalado, las recientes campañas de excavación se han practicado en la zona denominada "Pasillo", uno de los escasos sectores que aún cuentan con estratigrafía y que constituye una zona de paso entre el recorrido desde la entrada, que se efectúa por la Cueva Grande, hasta la salida, por la Cueva Chica. Esta zona, que se encuentra a unos $50 \mathrm{~m}$ de la boca de la Cueva Grande, carece de luz natural, muestra una fuerte pendiente y desde ella se accede inmediatamente al "Corredor de las Pinturas" y a la "Rampa", donde se localizan la mayor parte de las pinturas en negro.

Queremos destacar que el "Pasillo" se encontraba casi totalmente colmatado cuando a finales de 1969 comenzaron los trabajos de acondicionamiento -escalones y luz eléctrica- para abrir la cueva al público, presentando a nuestra llegada una zanja abierta en el sedimento arqueológico para facilitar el paso de una zona a otra del recorrido de la cavidad. De no haberse casi colmatado, esta zona formaría (Fig. 1), junto con el "Corredor de las Pinturas", por un lado, y la "Rampa, por otro, una sala de cierta pendiente debido a la existencia de un caos de bloques sobre el que se fueron depositando los niveles arqueológicos a partir del $\mathrm{Pa}-$ leolítico Medio. Posiblemente parte de este espacio se cerrara hacia la mitad y en la zona central por la unión del techo del Pasillo, en declive, con algunos bloques de mediano tamaño, facilitando la filtración de agua el desarrollo de algunas formaciones que contribuyeron al cerramiento, quedando a ambos lados los ramales del "Corredor de las Pinturas" y la "Rampa", entre cuyos intersticios se accedía hasta el fondo de la cueva antes de la construcción de los escalones, contando el 


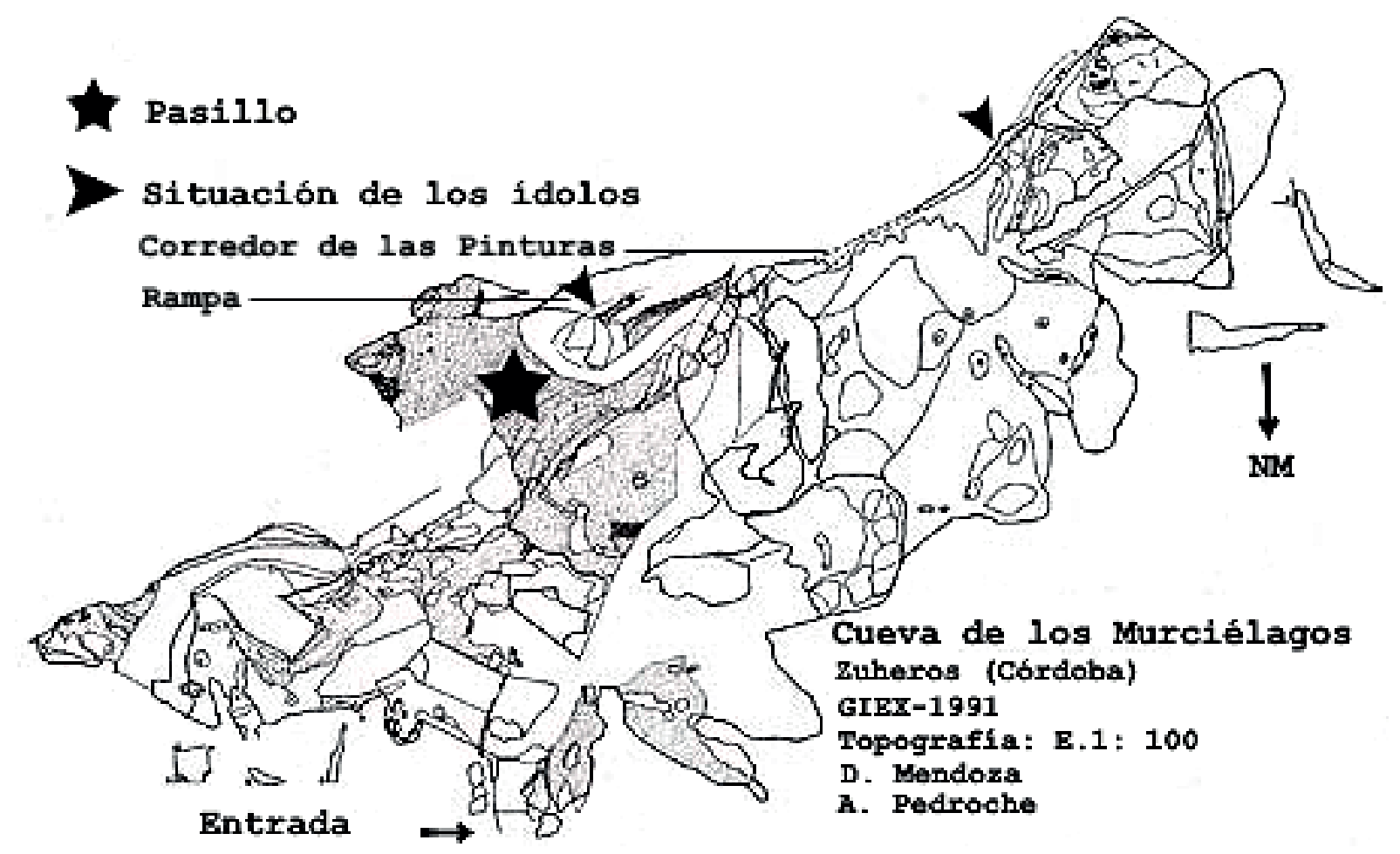

Figura 1: Planta del "Vestíbulo" de la Cueva Grande. Situación del "Pasillo", los “ídolos" y el "Corredor de las Pinturas".

primero de ellos con otro acceso hacia el interior a través de un corredor en cuyo recorrido hay que salvar varios desniveles para llegar a la "Sala de las Formaciones". De hecho, la "Rampa" y el "Corredor de las Pinturas", como consecuencia del relleno arqueológico existente en el "Pasillo", ofrecen una continuación del mismo, interrumpiéndose la deposición por la inclinación del techo del "Pasillo", por el caos de bloques que hay al final de sendos ramales y por presentar el comienzo del citado corredor con desniveles una pendiente ascendente.

Ciertamente, la inclinación del techo del "Pasillo", que al comienzo de nuestras excavaciones se encontraba a unos $50 \mathrm{~cm}$ del nivel de superficie, forma, a continuación y a la derecha, la pared del "Corredor de las Pinturas", con las representaciones de cápridos, entre otros motivos, y el "ídolo" al fondo, siendo el mismo techo que el de la "Rampa", donde se encuentra otra representación simbólica que analizamos en este trabajo. En realidad, este último sector es parte del propio "Pasillo", debiéndose su denominación a la necesidad de separar por zonas los restos materiales procedentes de superficie recuperados durante la limpieza general de la cueva que efectuamos en 1990.

\section{Hogares}

Pese a que las excavaciones se han efectuado en una zona que no corresponde a un lugar de habitación dada la ausencia de luz natural, la alta humedad y la pronunciada pendiente del "Pasillo", sin embargo se llevaron a cabo determinadas actividades antrópicas a lo largo del Neolítico (Gavilán et alii. 1996), como ya se ha expuesto en el apartado anterior al referirnos a las estructuras en fosa del bloque B y los escalones del C. Finalmente, en los niveles iniciales del Neolítico A se encendieron varios hogares (Gavilán et alii 1996; Vera y Gavilán 1999), habiéndose documentado cinco hasta la actualidad.

En la campaña de 1991 se excavó el primero de ellos, en el nivel 8-b de la cuadrícula A-0-1 (Lám. I-A) (Gavilán y Vera 1992); en la de 1993 se documentaron dos, ambos en la cuadrícula B-4 y en el nivel 8-B (Lám. II-A), superpuestos y separados por un nivel intermedio de escasos $3 \mathrm{~cm}$ de potencia, presentándose rubefactada la tierra infrapuesta a ellos (Lám. II-B); y en la de 2002 otros tantos y en similar posición estratigráfica a los anteriores, uno en el nivel " 13 clastos" de C-5 (Lám. I-B) y el otro en el "14 2a alzada" de C-4-5, que no quedó reflejado en el corte. 

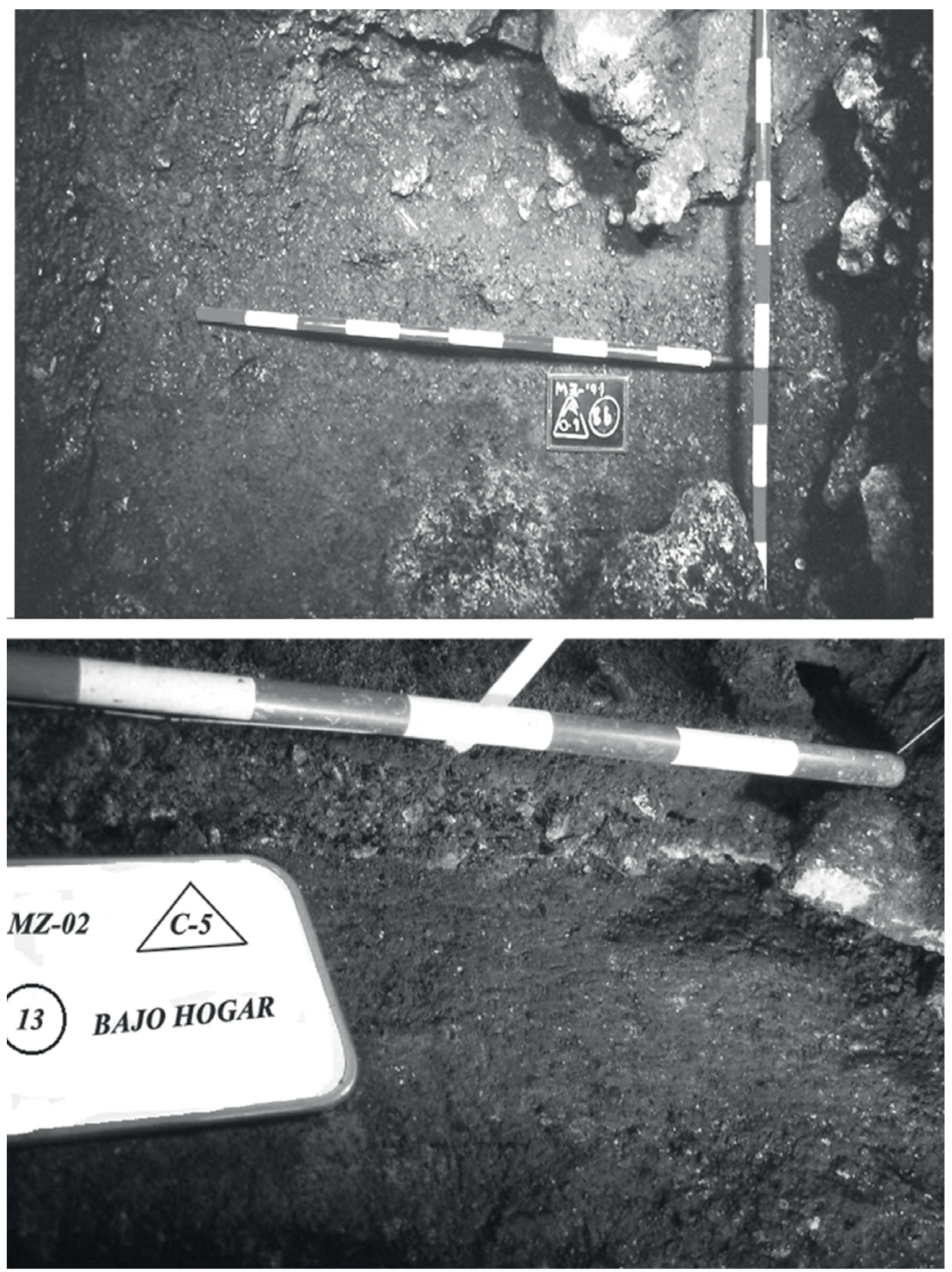

Lámina I: Hogares. A (superior): Hogar excavado en 1991.

B (inferior): Capa de cenizas pertenecientes al primer hogar de la campaña de 2002. 

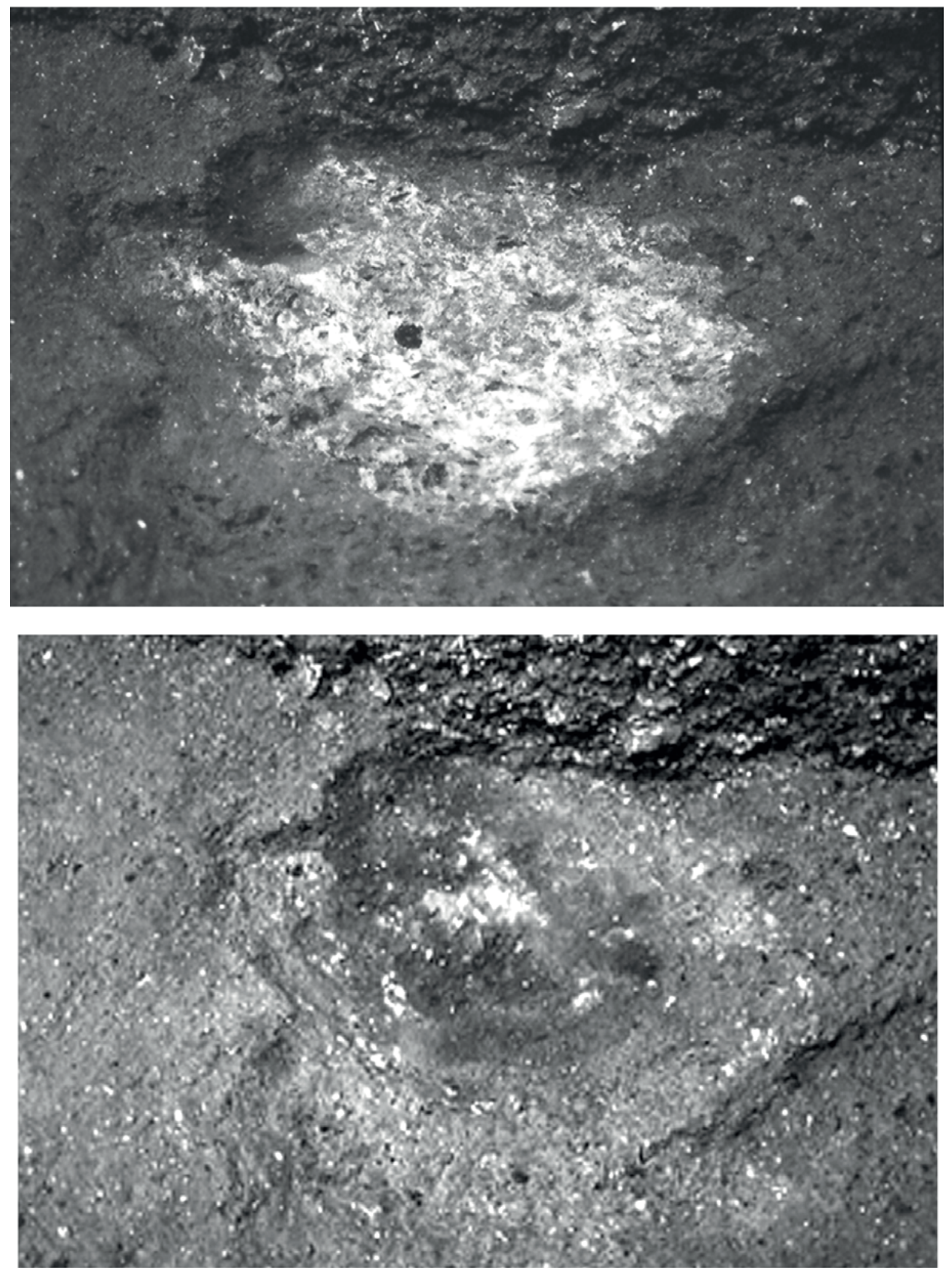

Lámina II: Campaña de 1993. A (superior): Hogar. B (inferior): Tierra rubefactada. 
Todos estos hogares se encuentran en los niveles más antiguos pertenecientes al comienzo del establecimiento de las primeras sociedades productoras en esta cueva; concretamente, los niveles infrapuestos tanto al hogar del nivel 8-b de A-01 como al del nivel 14 de C-4-5 inician la escasa serie de UU.SS. de Paleolítico Superior. Cabe destacar que la fecha obtenida para el nivel inmediatamente superpuesto al hogar superior de la campaña de $1993,4.310 \pm 120$ a.C. (I-17.773, carbón), se encuentra muy próxima a las de niveles sucesivos e infrapuestos al hogar inferior: $4.320 \pm 120$ a.C. y $4.360 \pm$ 120 a.C. (I-17.774, I-17.776, respectivamente, carbón), y que la obtenida en un nivel posterior, si bien no directamente superpuesto, al hogar excavado en 1991, resulta muy cercana a las anteriores: 4.240 a.C. (I-17.771, carbón). Estas dataciones tan contiguas señalan, sin duda, una reiteración de ciertas actividades intencionadas en este concreto sector de la cavidad.

Los cinco presentan las mismas características: Pequeñas dimensiones, comprendidas entre 30 y $45 \mathrm{~cm}$., limitada potencia, entre 2 y $4 \mathrm{~cm}$, reducido espesor de la capa de cenizas y escasos carbones como consecuencia de una única y prácticamente completa combustión, y con la tierra infrapuesta rubefactada (Lám. II-B), evidenciando con toda claridad que aquella se realizó in situ. Excepto la ligera depresión de la base, no presentan un acondicionamiento previo, como puede ser la excavación de una cubeta o estar circundados de piedras. Todo esto, aunado a sus reducidas dimensiones, nos lleva a considerarlos como hogares no precisamente destinados a la preparación de alimentos de consumo cotidiano. Por otra parte, los cinco hogares están disociados de cualquier tipo de suelo de ocupación o interfacies que evidencie una exposición temporal o uso prolongado de las zonas próximas. Por último, el hecho de que se eligiera para estas combustiones un sector que no reúne buenas condiciones de habitabilidad, pese al diferente aspecto que debía ofrecer el espacio en el que se ubican, permite pensar que la función principal tampoco debió ser la de acondicionamiento, es decir, la de proporcionar calor en la zona destinada a hábitat, como indicábamos en un trabajo anterior (Vera y Gavilán 1999), empero, entonces no alcanzamos a comprender su funcionalidad. Actualmente, tras relacionarlos con otros restos, determinadas manifestaciones simbólicas y contar con dos hogares más, creemos que formaron parte de unas actividades rituales.

Resulta conveniente tener en cuenta que cuando se encendieron estos hogares la distancia entre la superficie del suelo y el techo del actual "Pasillo" era de unos $2 \mathrm{~m}$; de igual modo, la existente entre la superficie del suelo tanto del "Corredor de las Pinturas" como de la
"Rampa" era asimismo superior, siendo posible tener una mejor panorámica de todo el techo y pared de este espacio, pero sin estar aquel tan elevado como para dificultar un uso del mismo.

No queremos terminar este apartado sin resaltar que el hogar excavado en 1991, por el momento el único que ha sido analizado en profundidad, proporcionó unos interesantes restos de materia orgánica, sobre los que tratamos seguidamente.

\section{Papaver somniferum y otros}

Indiscutiblemente, el no haber podido excavar en una zona de habitación ha condicionado la posibilidad de documentar vestigios de determinadas actividades, como las de carácter doméstico, siendo quizá también una de las causas de la relativa escasez de semillas detectadas pese a la criba de agua a que fue sometido todo el sedimento, a lo que hay que sumar que el grado de conservación de las mismas no era el más óptimo, imposibilitando su identificación en ocasiones. Pese a estos inconvenientes, se han registrado, por el momento, diferentes tipos de trigo (Triticum aestivum/durum, T.monococcum/dicoccum y T. dicoccum) y cebada (Hordeum vulgare), como plantas cultivadas, y cáscaras bellotas (Quercus sp.), aceitunas de acebuche (Olea europaea ssp. oleaster), y alcaparrones (Capparis sp.), como silvestres de utilización económica; junto a ellas, se documentaron otras plantas adventicias asociadas a cultivos, pero, sin duda, la especie más abundante es la $\mathrm{Pa}$ paver somniferum L. (Peña-Chocarro 1999; González et alii 2000), la adormidera, cuyas semillas están presentes en toda la secuencia correspondiente a las primeras sociedades productoras, tratándose, por momento, de los restos más antiguos presentes en la Península Ibérica. $\mathrm{Si}$, como nos planteamos en este trabajo, relacionamos estas semillas con los hogares, otros ítems y elementos simbólicos, ciertamente no habremos documentado actividades estrictamente domésticas en este sector de la cueva, pero sí quizá otras menos cotidianas.

Como hemos señalado más arriba, el hogar excavado en 1991 (nivel 8-b de A-0-1) es el único que por el momento ha sido sometido a un exhaustivo análisis, detectándose entre sus cenizas y carbones la presencia de 1 grano de cereal indet., una semilla de Silene sp. (alcaducea o colleja), 49 semillas de Papaver somniferum L. - pero no restos de la cápsula o de cualquier otra parte de la planta-, 2 fragmentos de tejido y $1 \mathrm{mi}-$ núsculo resto de materia orgánica quemada (González et alii 2000; Peña Chocarro 1999). El análisis morfológico de este último resto ha revelado una composición 


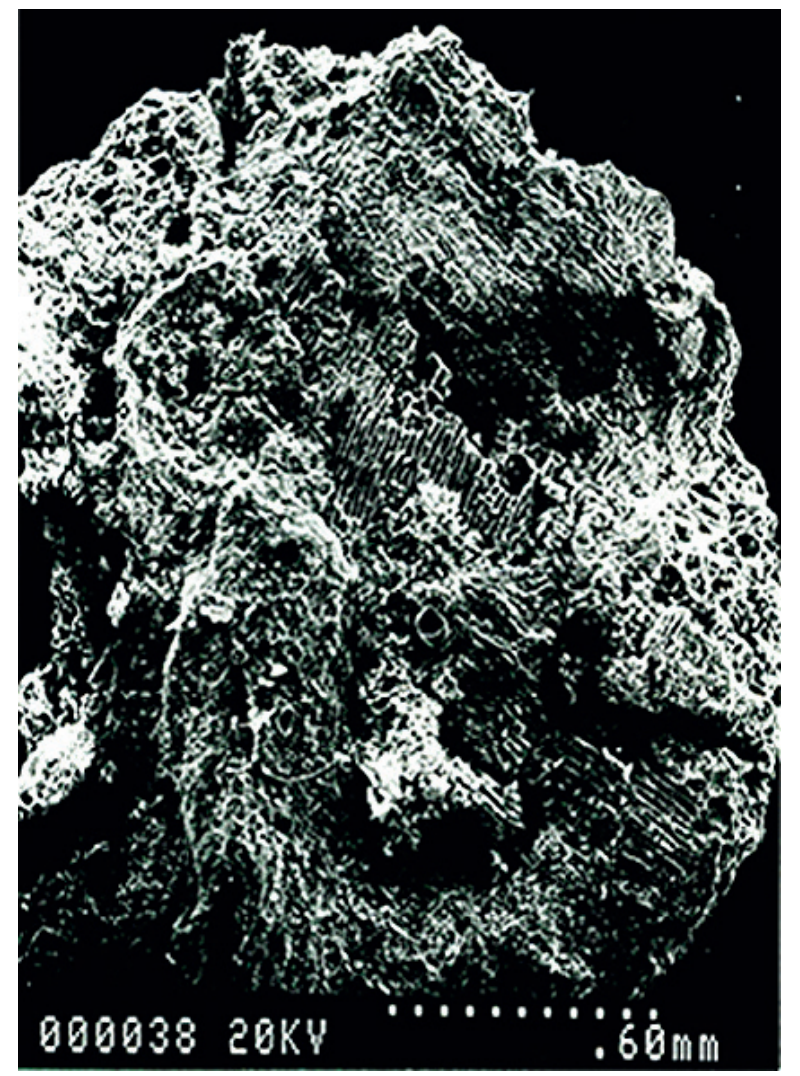

Lámina III: Resto orgánico -vómito-recuperado en el hogar de la campaña de excavación de 1991.

en la que están presentes semillas -cereales entre ellasmezcladas con saliva como consecuencia de la masticación, o bien jugos gástricos, sin que haya sido posible alcanzar un mayor grado de identificación así en las semillas, aunque se observan bien las células alargadas de la epidermis de los cereales, como en el resto de su composición (Láms. III y IV). No obstante, no descartamos un nuevo análisis más completo.

En lo que se refiere a este fragmento orgánico, en un primer momento se barajaron dos posibilidades: De un lado, podría tratarse de un resto de papilla, a base de cereales ya masticados, destinada a la alimentación de un individuo infantil en proceso de destete, en este caso habría que pensar en saliva; de otro, podría pertenecer a un trozo de vómito, en cuyo caso entrarían en su composición los jugos gástricos. Actualmente nos parece mucho más viable la segunda posibilidad, considerándolo una porción de vómito ya que, como hemos indicado, no estamos ante una zona de habitación y sería poco probable, dadas las características del sector -sin luz natural y en una zona de considerable pendiente-,

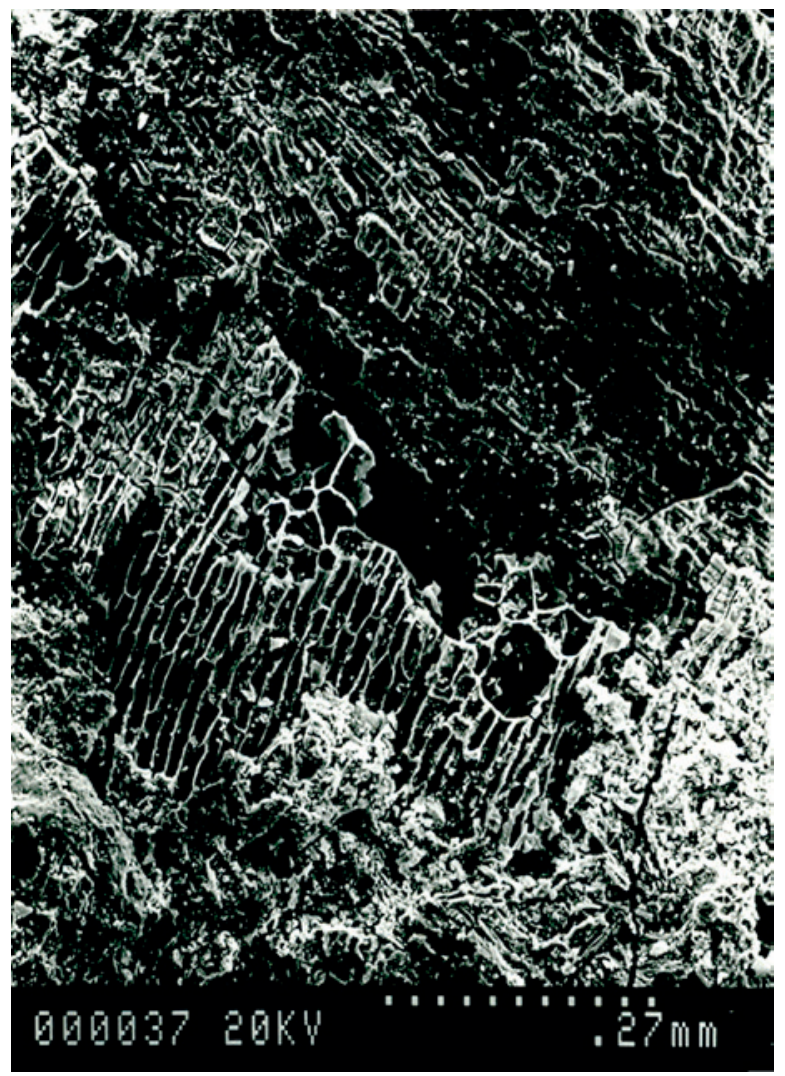

Lámina IV: Detalle del vómito.

que la alimentación de individuos infantiles de corta edad se llevase a cabo aquí, tratándose, además, de hogares que no parecen estar destinados a la preparación de alimentos cotidianos ni a proporcionar calor constante por sus reducidas dimensiones y su ubicación. Por otra parte, y abundando en esta última consideración, es importante tener en cuenta la presencia de bastantes semillas de Papaver somniferum en el mismo hogar, siendo factible pensar que dicha planta, en parte o en su totalidad, quizá obteniendo su jugo -el opiomasticando la cápsula, se hubiera consumido en torno a la combustión, echándose las semillas al fuego cuando aquella casi finalizaba, hecho que contribuyó a su buen estado de conservación.

Aunque sobradamente conocido, queremos señalar que la ingesta de Papaver somniferum mediante cocción actúa como analgésico y tranquilizante (Escohotado 1989), que el consumo de opio en dosis tóxica ocasiona, entre otros efectos, náusea con bastante asiduidad (Rivera y Obón de Castro, 1991), sobre todo en individuos neófitos, y que la adormidera posee principios activos 
también en el tallo y las hojas, aunque más atenuados, mientras que las semillas están "prácticamente desprovistas de alcaloides" (Escohotado 1989, T. 1: 90). Pensamos, pues, que la masticación e ingestión de parte de esta planta, principalmente de la cápsula -en cuyas paredes y tabiques se encuentra el opio-, puede explicar la presencia del resto de vómito en el hogar si la dosis de la ingesta fue alta o se consumía por vez primera.

En el trabajo que Garrido y Muñoz (2000) dedican a las cerámicas campaniformes con motivos simbólicos señalan la existencia de posibles ritos, previos a la llegada del campaniforme a la Península Ibérica, a partir de la presencia de semillas de Papaver somniferun en yacimientos neolíticos, como la Cueva de Zuheros (Peña Chocarro 1999; González et alii 2000), la del Toro, en Málaga (Buxó 1997), Murciélagos de Albuñol (Alfaro 1980), ritos en los que intervendría el consumo tales sustancias alucinógenas, plasmándose manifestaciones artísticas en las paredes de abrigos rocosos y otros espacios, como los funerarios. Estos ritos facilitarían posteriormente, con la llegada del campaniforme, "la comprensión del nuevo ceremonial de elite basado en la libación de alcohol por parte de los grupos peninsulares" (Garrido y Muñoz 2000: 295), introducción que supondría un cambio en el empleo de las plantas alucinógenas locales, que pasarían de inhalarse o fumarse a ingerirse en forma líquida, conllevando una interacción con las prácticas locales que daría lugar a un sincretismo (Sherrat 1995). Garrido y Muñoz (2000) plantean que las cerámicas campaniformes ibéricas decoradas con motivos simbólicos representan este sincretismo. Sin embargo, a partir de los datos que ofrecemos en este trabajo, planteamos que el consumo de sustancias enteógenas procesadas en forma líquida no tiene necesariamente que comenzar en la Península Ibérica con el campaniforme, sino que pudo existir, como mínimo, desde el Neolítico.

Por último, cabe destacar que el consumo de la $\mathrm{Pa}$ paver somniferum se ha constatado con fines terapéuticos en varios individuos exhumados en el complejo minero de Can Tintorer, observándose en el sarro dental de uno de ellos la presencia de restos de la cápsula, cuya masticación ocasionó la ingesta del látex (JuanTresserras y Villalba 1999; Juan-Tresserras 2000).

\section{Cerámicas}

Murciélagos de Zuheros ha proporcionado unos conjuntos cerámicos variados y realmente abundantes, sobresaliendo las cerámicas a la almagras; sin embargo, con ser estos recipientes de una calidad excepcional, no son los que presentan las peculiaridades más excepcionales en cuanto a los temas decorativos y elementos integrantes, sino un reducido número de cerámicas incisas, asociadas a impresiones, que fueron objeto de estudio hace algunos años (Gavilán y Vera 1993). Nos estamos refiriendo a las cerámicas con decoración simbólica a base de representaciones faciales que cuentan, en la parte interna y en correspondencia con la representación facial al exterior, con un cordón interior perforado situado en el labio.

Estos recipientes, extraídos durante los trabajos de acondicionamiento efectuados en la cueva -comenzados tras las excavaciones de 1969 y finalizados a principios de 1971-, carecen de contexto estratigráfico. En cuanto a su adscripción, hace poco más de una década (Gavilán y Vera 1993) nos decantamos por el Neolítico Medio, pero siendo conscientes de que a la fecha de elaboración del trabajo las excavaciones en Murciélagos de Zuheros no habían hecho nada más que comenzar, y no disponíamos de los suficientes datos. Actualmente, tras varias campañas, contamos con una información mayor a todos los niveles sobre la secuencia neolítica de esta cavidad, que nos permite un cambio de postura $\mathrm{y}$, como hemos expresado en varias ocasiones y en este mismo trabajo, abogamos por una ruptura en lo que se refiere a Murciélagos de Zuheros como exponente del Neolítico Medio andaluz. Por otra parte, como queda claramente expuesto en la introducción, los bloques A y B pertenecen cultural y cronológicamente a la fase antigua del período, al Neolítico Antiguo no cardial. Siendo con los restos cerámicos procedentes de los niveles que integran estos bloques con los que las cerámicas simbólicas guardan semejanza en su forma y características, distanciándose notoriamente de las aportadas por los niveles del bloque C. De este modo, nos pronunciamos por una adjudicación de Neolítico Antiguo para estos recipientes.

Entre las cerámicas simbólicas procedentes de Murciélagos destacan, por la semejanza de temas con el A.E.P., las $\mathrm{n}^{\mathrm{o}} 6$ y 6510. La primera de ellas (Fig. 2, A, $\left.n^{\circ} 6\right)$ muestra la representación de cejas, nariz y ojos -éstos mediante dos círculos concéntricos- en un esquema semejante al del "ídolo" (Lám. V, B) situado al final del "Corredor de las Pinturas", presentando lógicas variaciones que responden más al tipo de soporte que a la transmisión del concepto, aunque, ciertamente, el grado de esquematismo es superior en la imagen representada en la roca que en la vasija. Cuenta, además, con unas líneas verticales que parten de los ojos, que acercan también esta representación a la ubicada en la "Rampa" (Lám. V, A). Por su parte, la vasija $n^{\circ}$ 6510 ofrece (Fig. 2, B), atendiendo a la decoración que 

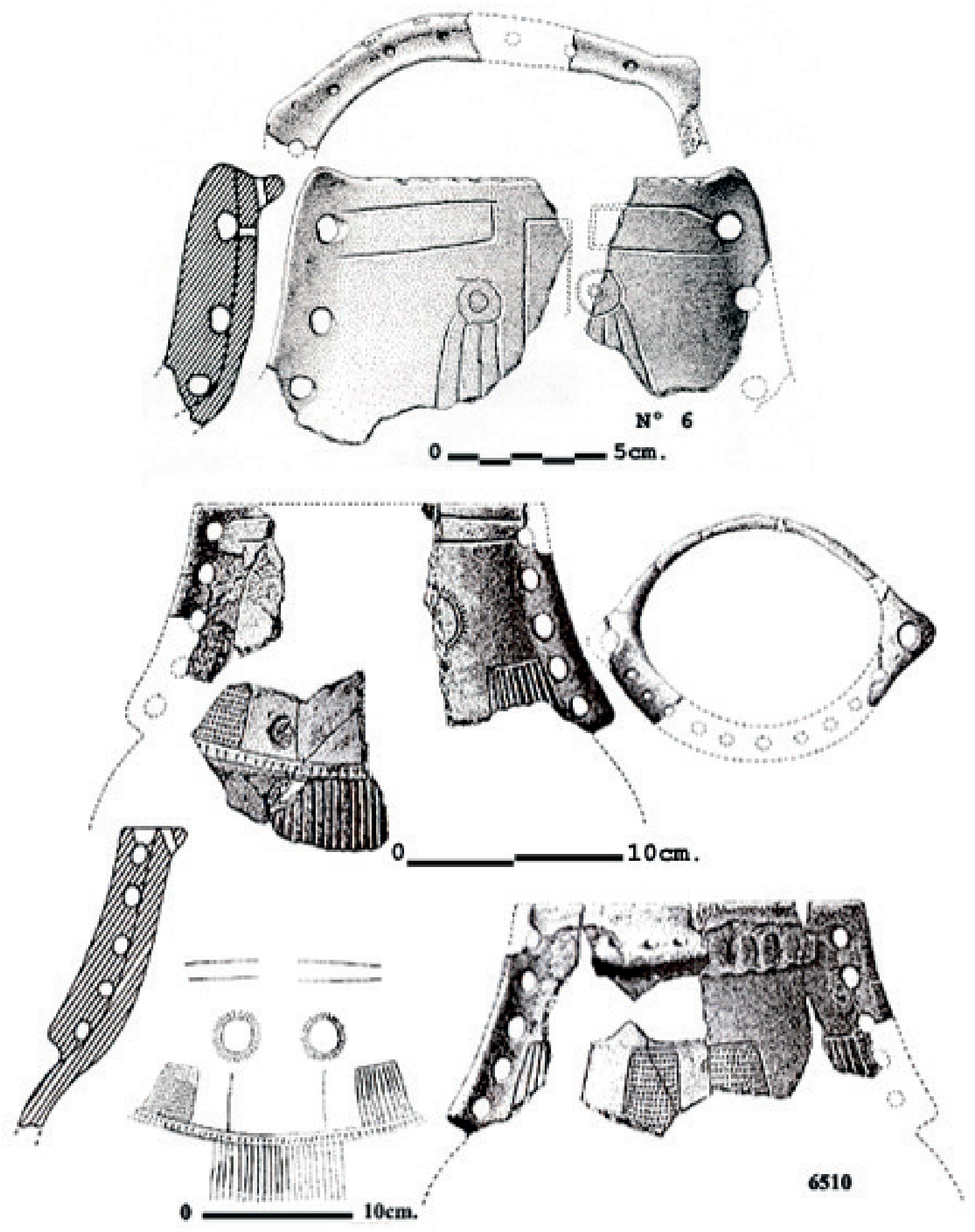

Figura 2: Cerámicas simbólicas procedentes de la Cueva de los Murciélagos. 


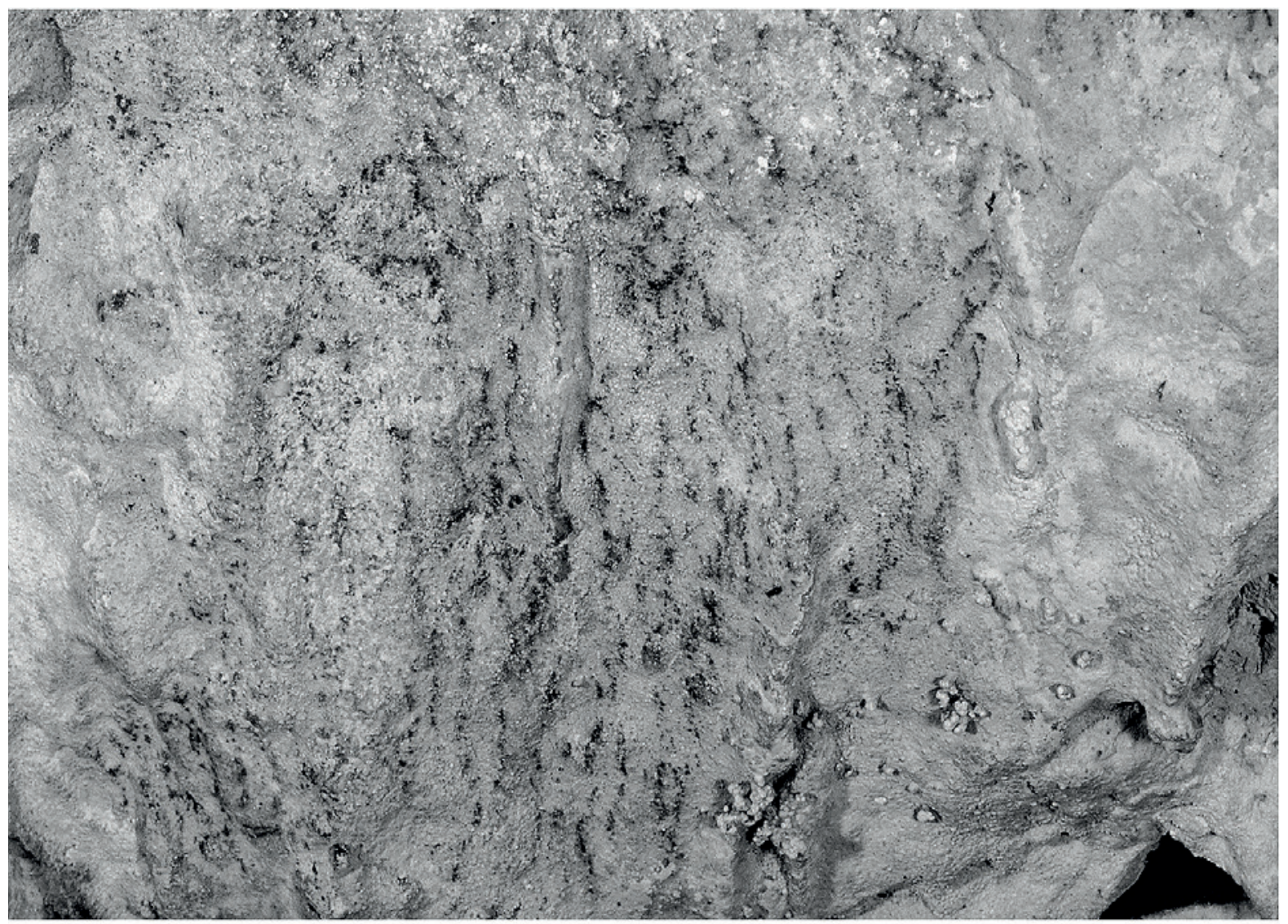

A

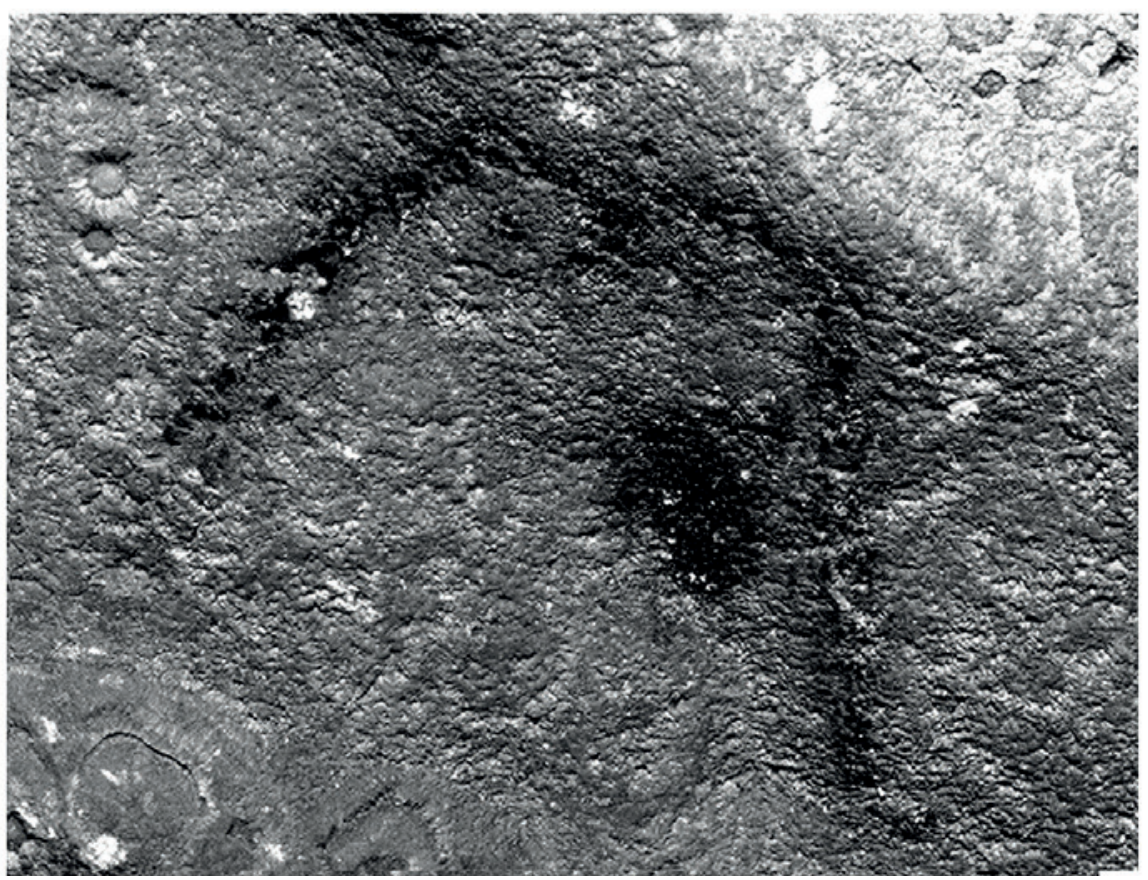

Lámina V: Representaciones de "ídolos". A: "Rampa". B: "Corredor de las Pinturas".

ISSN: 1133-4525 ISSN-e: 2255-3924 
muestran los fragmentos conservados, la representación de cejas y ojos, en este caso ejecutados a manera de esteliformes, de los que posiblemente partía, al menos, una línea vertical; se aprecia, además, como, a ambos lados de los esteliformes y en una posición ligeramente inferior, se encuentran, en un lado, una línea horizontal de la que arrancan varias verticales, a modo de pectiniforme, y en el otro unas impresiones enmarcadas, finalizando en una banda horizontal incisa rellena de impresiones de la que, a su vez, parten una serie de líneas verticales que afectan a la zona central del galbo de la vasija. En la cara opuesta, y debajo de una tercera asa multiforada, se repiten las impresiones enmarcadas y los pectiniformes. En conjunto, el tema de estas vasijas responde a una faz humana de alto contenido simbólico.

Junto a los anteriores recipientes, queremos indicar la existencia de otros cuya decoración muestra, según las porciones conservadas, temas similares, o bien participan del cordón interior perforado pero sin representaciones faciales, sino con motivos geométricos (Gavilán y Vera 1993), muy en la tónica de los documentados en algunas cuevas del País Valenciano, como l'Or y Sarsa, entre otras, que ofrecen motivos antropomorfos, zoomorfos y geométricos en recipientes adscritos al Neolítico Antiguo levantino, o la vasija procedente de Gavá (Bosch y Estrada 1994), adjudicada al Neolítico Medio, que muestra la representación de una figura humana femenina.

Cabe decir que algunos yacimientos neolíticos en cueva con cerámicas decoradas mediante temas de fuerte contenido simbólico, caso de l'Or y Sarsa, se consideran como lugares de culto, independientemente de su ocupación como lugar de hábitat y/o enterramiento, relacionándose con los santuarios situados en los abrigos rocosos que ofrecen los mismos temas en sus paredes, de tal manera que aquellas formarían parte de un conjunto de estaciones donde se celebrarían las prácticas religiosas de estos grupos y las ceremonias destinadas a reforzar sus lazos y cohesión (Martí, 2002, en M. Hernández y J.Ma . Segura, Coord.), planteamiento que compartimos con los autores. En este sentido debemos resaltar que Murciélagos de Zuheros no sólo cuenta con recipientes cerámicos con temas simbólicos, como los que aquí exponemos y hemos dado a conocer más ampliamente (Gavilán y Vera 1993), sino que dichos temas en soporte cerámico presentan, además, unos paralelos incontestables con las representaciones de ídolos existentes en las paredes del interior de la propia cueva.

Atendiendo a estos dos aspectos, Murciélagos de $\mathrm{Zu}$ heros actuó como santuario para, al menos, las primeras sociedades productoras establecidas en ella. Pero la cueva ha aportado, como venimos indicando, otros restos no menos interesantes, como los hogares, y que redundan en la consideración de parte de ella como espacio sagrado, al menos en los comienzos de dicha ocupación.

En cuanto a la funcionalidad de las cerámicas con decoración simbólica, Martín y Camalich (1982), al analizar las del Calcolítico, rechazan su uso como recipientes destinados exclusivamente a rituales al encontrarse indistintamente en contextos habitacionales y funerarios. Sin embargo, como muy bien indican Garrido y Muñoz (2000) -basándose en Hodder (1982)- al referirse a las cerámicas simbólicas campaniformes, los rituales no se restringen a la esfera funeraria, sino que se practican también en la de los vivos. De hecho, se relaciona el uso de estos recipientes con el consumo de ciertas bebidas, que se ingerirían durante el transcurso de ceremoniales y por parte de un sector de la población.

\section{Manifestaciones pictóricas simbólicas}

Aunque el A.E.P. parietal que alberga la Cueva de los Murciélagos de Zuheros es variado tanto en su temática como en el color del pigmento utilizado, negro y rojo - este último característico de los abrigos rocosos y menos frecuente en el interior de cavidades-, vamos a centrarnos en este trabajo sólo en las representaciones de ídolos, paralelizables con las decoraciones cerámicas. Este tipo de manifestaciones, en negro, se localiza en dos sectores concretos de la cueva, en el "Corredor de las Pinturas" y en la "Rampa".

En el primero de ellos se encuentra el "ídolo" dado a conocer hace ya décadas por Bernier y Fortea (196869) como "ídolo-placa", que fue adjudicado al entonces denominado Bronce I hispano. Consta de una línea horizontal de la que parten, a cada extremo, dos verticales aunque ligeramente oblicuas y divergentes; del centro de la primera nace una tercera línea vertical de cortas dimensiones, a cuyos lados, y centrados en la parte superior con respecto a la totalidad del conjunto, se encuentran dos pequeños puntos. La figura total ofrece, sin duda, la representación, simple pero clara, de una faz (Lám. V, B).

Este motivo se plasmó en un caos de bloques existente al final del Corredor de las Pinturas", desde donde se accede a la "Sala de las Formaciones" por dos ramales. Por el primero y antes de que se abriese paso entre el caos de bloques, se descendía por estrechos vanos en el mismo, resultando la manifestación perfectamente visible al encontrarse a escasos $50 \mathrm{~cm}$ del primer vano a salvar; y por el segundo a través de un corredor de acceso fácil pero con varios desniveles, quedando la 
figura abajo y a la izquierda, lo que dificultaría su contemplación de no conocerse su exacta ubicación. En cualquier caso, el "ídolo", junto con un cuadrúpedo en rojo situado a su derecha y a escasos $\mathrm{cm}$, se encuentra justo antes de estrecharse el recorrido de la cueva hacia el interior y al final del "Corredor de las Pinturas", no habiéndose localizado, al menos por el momento, representaciones pictóricas a mayor profundidad.

Por su parte, en la "Rampa" se encuentran algunos motivos de difícil definición entre los que destaca una figura bastante más elaborada y compleja que la representación anterior. A partir de un resalte vertical de escaso grosor de la pared caliza se articula una representación un tanto insólita. A cada lado del resalte, y prácticamente equidistantes, se encuentran dos círculos de tendencia ovoide de los que parten, en distintas direcciones, varias líneas cortas, y a unos escasos $\mathrm{cm}$ de aquellos se inicia una amplia serie de líneas verticales (Lám. V, A). Nosotros interpretamos este motivo como la representación de un "ídolo" ante la clara semejanza que ofrece con los temas presentes en al menos dos de los recipientes con decoración simbólica, las $n^{\circ} 6$ y 6510 (Fig. 2, A y B).

Esta manifestación se encuentra a 1'5 m escaso del ángulo SO de la cuadrícula A de la excavación del "Pasillo", y junto con otras, también en negro y nada usuales, son las últimas de la "Rampa", no conociéndose más manifestaciones hacia el interior.

Así, pues, este tipo de figuras se localizan muy próximas aunque en diferentes corredores y, como hemos señalado, ambos debieron formar parte del mismo sector de la cueva antes de que el final del "Pasillo" se cerrase a consecuencia del declive de su techo y de que el sedimento arqueológico fuese casi colmatándolo, tratándose de las últimas manifestaciones pictóricas plasmadas que preceden los accesos hacia el interior por estrechos pasos. En cualquier caso, ambas representaciones, si bien diferentes en su forma, se encuentran próximas a la zona de excavación, es decir, cercanas al lugar donde se encendieron los hogares, sobre todo la ubicada en la "Rampa", eligiéndose para el emplazamiento de ésta una zona actualmente oculta al estar debajo de un reborde de la pared, pero que debía resultar más visible antes de la deposición de los niveles superpuestos a los diferentes hogares detectados en el bloque A, y para el ídolo del "Corredor de las Pinturas" un lugar previo al estrechamiento de la cavidad.

En el estudio que uno de los firmantes realizó sobre las cerámicas simbólicas (Gavilán y Vera 1993) de la propia cueva, planteamos la posibilidad de que las representaciones de "ídolos", generalmente adscritos al Calcolítico, se iniciasen a comienzos del Neolítico al observar la similitud existente entre la figura plasmada en el "Corredor de las Pinturas" y la que muestran algunos de dichos recipientes, planteamiento que seguimos defendiendo.

\section{Consideraciones finales}

Hasta aquí hemos expuesto los restos cerámicos y orgánicos, hogares y manifestaciones simbólicas que pensamos pueden relacionarse para ofrecer una explicación de la presencia de la mayoría de ellos en un espacio tan concreto de la Cueva de los Murciélagos, precisamente una cavidad de gran amplitud.

Sin duda, estamos ante un yacimiento neolítico excepcional tanto por la ingente cantidad de material que ha aportado, que sobrepasa con mucho lo que puede ser considerado normal para los comienzos de las primeras sociedades productoras, como por la calidad de los mismos y el carácter verdaderamente inusual de algunos de ellos, v. gr., las propias cerámicas simbólicas. La presencia de estos recipientes y/o determinadas manifestaciones artísticas de contenido claramente "simbólico", o de determinadas combustiones en un yacimiento, ya mueve a la posibilidad de considerar la existencia de un espacio de carácter ritual en el mismo.

Así, en relación con los hogares, queremos señalar que el uso del fuego en rituales neolíticos de enterramiento se viene constatando desde hace algún tiempo. Varias cuevas han proporcionado enterramientos con claras evidencias de cremación, entre ellas la de la Dehesilla (Arcos de la Frontera, Cádiz), de donde procede un cráneo perteneciente a un individuo "adulto con indicios de cremación" localizado en los niveles correspondientes al Neolítico Antiguo B (Acosta y Pellicer 1990: 88). A partir del Neolítico Final se dispone de mayor documentación acerca de la utilización del fuego en los enterramientos colectivos, megalíticos o en cuevas, y está siendo constatado en diferentes sectores peninsulares (Rojo-Guerra y Kunst 2002); dicho ritual va desde la cremación parcial o completa del cadáver, al empleo del fuego en el espacio funerario en diferentes grados, llegándose a la destrucción intencionada por ignición de todo el monumento en caso de sepulcro (Gutiérrez, Gómez y Ocaña 2002, en Rojo y Kunst, eds.), como se ha podido documentar, entre otros, en la Peña de la Abuela y El Miradero (Delibes y Etxeberria 2002, en Rojo y Kunst, eds.).

Por su parte, Fábregas (1988), al tratar de los fuegos previos situados bajo algunos túmulos, señala que pueden responder a una limpieza de la zona o a rituales de fundación. Una explicación en cierta medida semejante 
es la que hemos planteado para los hogares, y otras estructuras y elementos presentes en el yacimiento previo a la construcción del Dolmen de las Casas de Don Pedro, señalando la relación de tales elementos con la erección de un primigenio menhir, al que se añade un segundo poco tiempo después, que actuarían, por una parte, como hito territorial perteneciente a un grupo productor de mediados del V milenio -sin calibrar-, que simboliza así la regulación de los derechos al acceso a la tierra y los recursos, y, por otra, como indicadores de espacios sagrados a través de la celebración de ciertos rituales, manifestándose la continuidad de su carácter sagrado mediante la conversión de la estructura megalítica prefuneraria en dolmen de cámara simple $\mathrm{y}$, posteriormente, en dolmen de corredor (Gavilán y Vera 2005).

Independientemente de las distintas explicaciones ofrecidas sobre la existencia de estas combustiones, sus causas y finalidades según el contexto, nos interesa aquí el uso del fuego como componente importante de algún tipo de ritual, funerario, como en los enterramientos, o fundacional, asociado o no a elementos bien visibles en un territorio.

En el caso que nos ocupa, los hogares no se asocian a rituales de enterramiento -al menos no se ha documentado ningún depósito funerario en la zona excavada a lo largo de las diferentes campañas-, sino que, como hemos indicado al referirnos a ellos, estos cinco hogares de una única combustión se encendieron en los primeros niveles que inician la secuencia neolítica, no habiéndose detectado otros en los niveles medios y finales del bloque A, ni en los correspondientes a los bloques B y $C$; por otra parte, no se encuentran en un sector habitacional por las razones ya aducidas, sin embargo este espacio sí ofrecería amplitud merced a la unión del "Pasillo" con parte de la "Rampa" y del "Corredor de las Pinturas", previamente a la superposición de los diferentes niveles generados tras las primeras ocupaciones neolíticas, resultando adecuado para concretas actividades relacionadas con la religiosidad de estas sociedades.

La existencia de un espacio delimitado que debían formar estos tres sectores, junto con la presencia, por una parte, de representaciones de ídolos en los dos ramales del mismo que desembocan en los accesos hacia el interior de la cueva, y por otra, de los hogares, el fragmento de vómito y las semillas de Papaver somniferum en uno de ellos -precisamente en uno de los primeros que se encendieron-, nos lleva a considerar seriamente la conexión de todos ellos con las cerámicas simbólicas y la celebración de determinados rituales.

Desde hace algunos años estamos asistiendo a unos planteamientos que consideramos particularmente interesantes. De un lado, la posible relación existente entre el consumo de sustancias enteógenas y la plasmación de manifestaciones artísticas (Bradley 1989); de otro, el uso de recipientes con decoración simbólica, campaniformes o no (Garrido y Muñoz 2000), en ceremoniales en los que interviene la ingesta de ciertas bebidas; sin embargo, la interconexión entre todos los citados elementos se ha hecho tomando datos procedentes de diferentes yacimientos peninsulares. En nuestro caso, semillas de Papaver somniferum y manifestaciones artísticas se encuentran no sólo en el mismo yacimiento, sino en un común y concreto sector del mismo, en el que también se encendieron los cinco hogares, aportando uno de ellos el resto orgánico que venimos considerando como parte de un vómito. Opinamos que la presencia de todos estos elementos no es aleatoria. Antes al contrario, resultan más que suficientes y significativos, desde nuestro punto de vista, para plantear que pudieron formar parte de un ritual, en cuya intervención incluimos las cerámicas simbólicas, pensando que su funcionalidad, en buena lógica ante la temática que exhiben, no estaría destinada a actividades relacionadas con la vida cotidiana, sino que su uso quedaría reservado a rituales y eventos importantes para estas sociedades. Al respecto, queremos recordar que en algunos sectores europeos determinaos recipientes, como los "quemaperfumes" chassenses, se relacionan con la combustión del opio, que formaría parte importante de ciertas celebraciones de carácter ritual, en este caso de enterramiento (Knapp 1991).

No queremos soslayar la presencia de recipientes de semejantes características procedentes de otras cavidades de la Subbética Cordobesa, como el de Cueva Negra, que presenta similar forma y cordón interior perforado, y el de la Cueva del Muerto, con representación facial y cordón interior perforado. En esta última cavidad se expolió un enterramiento, retirándose una serie de restos materiales, entre ellos ese fragmento de vasija, cuya conexión con los restos óseos humanos no hemos podido establecer (Gavilán 1989a) al tratarse también de una cueva de ocupación estacional. Otra cueva, la de la Murcielaguina (Gavilán 1989b), proporcionó una interesante vasija que ofrece como decoración unos temas propios del A.E.P. Estos recipientes podrían sugerirnos, a tenor de lo que defendemos en este trabajo, celebraciones rituales, sin embargo, al tratarse de yacimientos que sólo han aportado hasta ahora materiales de superficie, no nos pronunciamos, pero quizá sea interesante tenerlos en cuenta para posibles ulteriores trabajos. Lo que sí están indicando es, sin duda, una unidad conceptual y religiosa, que quizá resulta posible extender a amplios sectores si tenemos en cuenta la existencia de recipientes con decoraciones simbólicas en Nerja (Pellicer 
y Acosta; en Jordá 1986) y ciertos “esteliformes" procedentes de otras cuevas malagueñas (Olaria 1977).

Retomando el tema de nuestro trabajo, y partiendo de la conjunción de las estructuras, los ecofactos -semillas de Papaver somniferum y vómito-, y la posible conexión entre éstos con las cerámicas y las manifestaciones simbólicas aquí analizadas, creemos que no resulta descabellado plantear la celebración de rituales relacionados, quizá y en un principio, con la fundación de un nuevo hábitat. $\mathrm{Al}$ respecto, nos parece importante recordar que dos de los hogares se encendieron en los niveles que marcan el comienzo de la ocupación de la cueva por parte de las primeras sociedades productoras, y bajo los cuales se inician ya las UU.SS. pleistocénicas.

Parte del rito pudo consistir en encender un simple hogar, sin precisar un previo acondicionamiento ya que su uso iba a ser limitado en el tiempo a juzgar por el escaso espesor tanto de la capa de cenizas como de la de los carbones, en el cual, entre otras, pudieron procesarse determinadas sustancias, alguna enteógena, como la Papaver somniferum, que pudo consumirse, como hemos señalado, mediante infusión o maceración, empleándose para ello los recipientes simbólicos como parte integrante del ritual, sin excluir la masticación e ingesta de la cápsula, a juzgar por el vómito, expulsándose algunas semillas al fuego. Con respecto a esto último, hemos de señalar que no se ha detectado entre los restos del hogar fragmentos de la pared de la cápsula, del tallo o de las hojas de dicha planta, y que la presencia del citado vómito en el mismo hogar apunta hacia un consumo intencionado de la misma más que hacia una inhalación del humo producido durante su combustión, que quizá hubiese requerido mayor tiempo de exposición al fuego, conllevando esto un deterioro en la conservación de las semillas.

Junto a este consumo y formando parte del ritual, planteamos la probable representación de los ídolos -no descartando totalmente la de otros motivos- en las paredes de este espacio que, a partir de la celebración del primer rito y a lo largo de parte de la ocupación correspondiente al bloque A, pudo albergar tales ceremonias, repitiéndose el ritual, quizá con ligeras modificaciones, con la finalidad de reforzar la cohesión y regular las relaciones intragrupales, siendo así como encontramos una explicación factible para los restantes hogares documentados en los niveles inmediatamente superpuestos pero correspondientes a los inicios del bloque A.

Todo esto redunda, aun más, en la unidad conceptual que se advierte, a nivel simbólico, entre el Neolítico y el Calcolítico, empleándose casi sin interrupción, aunque con presencia de otros detalles, los mismos temas: oculados, cuadrúpedos y esteliformes, principalmente y como motivos más simbólicos. Como indica Muñoz (1998) al tratar de estos rituales referidos a momentos inmediatamente posteriores, existe una clara tendencia hacia la restricción, en cuanto a uso y consumo de líquidos en los recipientes simbólicos del Calcolítico, que serviría para legitimar y remarcar las diferencias socioeconómicas en el seno de un mismo grupo. Sin embargo, en nuestro caso, estos ritos no irían encaminados exclusivamente a legitimar el estatus de escasos individuos en el sentido que alude el citado autor (Ibidem), sino a reafirmar la cohesión grupal, aunque cabe pensar que el acceso a estos rituales quedaría reservado a ciertos individuos, evolucionado posteriormente hacia esa restricción de carácter socioeconómico.

\section{BIBLIOGRAFÍA}

ACOSTA, P. y PELLICER, M. (1990): La Cueva de la Dehesilla (Jerez de la Frontera). Las primeras civilizaciones productoras en Andalucía Occidental. Jerez de la Frontera.

ALFARO, C. (1980): "Estudio de los materiales de cestería procedentes de la Cueva de los Murciélagos (Albuñol, Granada)", Trabajos de Prehistoria 37: 109-162.

BERNABEU, J.; PÉREZ, M. y MARTÍNEZ, R. (1999): "Huesos, Neolitización y Contextos Arqueológicos Aparentes", II Congrés del Neolític a la Península Ibèrica. Sagvntvm-Plav, Extra-2: 589-596.

BERNIER, J. y FORTEA, F.J. (1968-69): "Nuevas pinturas esquemáticas en la provincia de Córdoba. Avance a su estudio", Zephyrus XIX-XX: 143-164. Salamanca.

BOSCH, J.y ESTRADA, A. (1994): “La Venus de Gavà (Barcelona). Una aportación fundamental para el estudio de la religión neolítica del suroeste europeo" TP 51: 149-158.

BRADLEY, R. (1989): "Deaths and Entrances: A Contextual Análysis of Megalithic Art", Current Anthropology 30: 68-75.

BUXÓ, R. (1997): Arqueología de las plantas. Crítica, Barcelona.

CARBONELL, A. (1945): "Noticias varias recopiladas en los antecedentes de campo", Boletín de la Real Academia de Córdoba 54: 77-86.

DELIBES, G. y ETXEBERRIA, F. (2002): "Fuego y cal en el sepulcro colectivo de $<$ El Miradero $>$ (Valladolid): ¿accidente, ritual o burocracia de la muerte?", en Sobre el Significado del Fuego en los Rituales Funerarios del Neolítico (M Rojo y M. Kunst, eds.) Studia Archaeologica 91: 39-64. 
ESCOHOTADO, A. (1989): Historia General de las Drogas. 3 vol. Alianza Editorial, Madrid.

FÁBREGAS, R. (1988): “Cronología y periodización del megalitismo en Galicia y norte de Portugal", Espacio, Tiempo y Forma I, Prehistoria: 279-292.

GARRIDO, R. y MUÑOZ, K. (2000): “Visiones sagradas para los líderes. Cerámicas campaniformes con decoración simbólica en la Península Ibérica”, Complutum 11: 285-300.

GAVILÁN, B. (1989): El Neolítico en el Sur de Córdoba. Análisis Sistemático de las primeras culturas productoras. Anexos de Estudios de Prehistoria Cordobesa. 2 vol. Univ. de Córdoba.

- (1989): "Paralelismo entre la decoración cerámica y el arte esquemático parietal: Vasija de la Cueva de la Murcielaguina (Priego de Córdoba)", XIX Congreso Nacional de Arqueología (Castellón de la Plana, 1987) T.II: 229-236. Zaragoza.

- (1991): “Avance preliminar sobre la Excavación Arqueológica de Urgencia en la Cueva de los Murciélagos de Zuheros (Córdoba)", Antiqvitas 2: 17-25. Priego de Córdoba.

- (1997): "Reflexiones sobre el Neolítico Andaluz", Spal 6: 23-33. http://dx.doi.org/10.12795/ spal.1997.i6.02

GAVILÁN, B. y VERA, J.C. (1992): "Breve avance sobre los resultados obtenidos en la excavación arqueológica de urgencia en la Cueva de los Murciélagos de Zuheros (Córdoba)", Antiquitas 3: 23-30. Priego de Córdoba.

- (1993): “Cerámicas con decoración simbólica y cordón interior perforado procedentes de varias cuevas situadas en la Subbética Cordobesa", Spal 2: 81-108. http://dx.doi.org/10.12795/spal.1993.i2.03

- (2001): "El Neolítico en la Alta Andalucía: Cuestiones sobre la caracterización de sus fases", Spal 10: 177-183. http://dx.doi.org/10.12795/spal.2001. i10.11

- (2005): "Neolítico y Megalitismo prefunerario en Andalucía”, III Congreso de Neolítico en la Península Ibérica (Santander, 5-8 de octubre de 2003.) (P. Arias, R. Ontañón, C. García-Moncó, eds.), Monografias del Instituto Internacional de Investigaciones Prehistóricas de Cantabria.1. 535-541.

GAVILÁN, B.; VERA, J.C.; PEÑA, L.; CEPILLO, J.J.; DELGADO, M.R. y MARFIL, C. (1994): "Preliminares sobre la tercera campaña de Excavación Arqueológica de Urgencia en la cueva de los Murciélagos de Zuheros (Córdoba)", Antiqvitas 5: 5-12. Priego de Córdoba.

GAVILÁN, B.; VERA, J.C.; PEÑA, L. y MAS, M. (1996): "El V y el IV Milenios en Andalucía Central: La
Cueva de los Murciélagos de Zuheros (Córdoba). Recientes aportaciones", I Congrés del Neolític a la Península Ibèrica. Formació e implantació de les comunitats agrícolas (Gavá-Bellaterra, 1995) Actes. Vol. I (J.Bosch, M. Molist. Orgs.), Rubricatum 1: 323-327. GONZÁLEZ, J.E.; IBÁÑEZ, J.J.; PEÑA, L.; GAVILÁN, B. y VERA, J.C. (2000): “El aprovechamiento de recursos vegetales en los niveles neolíticos del yacimiento de los Murciélagos (Zuheros, Córdoba)", Complutum 11: 171-189.

GUTIÉRREZ, C.; GÓMEZ, A. y OCAÑA, A. (2002): "Fuego y ritual en el enterramiento colectivo de Cueva Maturra (Argamasilla de Alba, Ciudad Real)", en Sobre el Significado del Fuego en los Rituales Funerarios del Neolítico (M. Rojo y M. Kunst, Eds.). Studia Archaeologica 91: 99-126.

IBÁÑEZ, J.J. y GONZÁLEZ, J.E. (1996): “El uso de los útiles en sílex de los niveles neolíticos de la cueva de $<$ Los Murciélagos $>$ (Zuheros, Córdoba). Primeros resultados", I Congrés del Neolitític a la Península Ibèrica. Formació e implantació de les comunitats agrícoles (Gavá-Bellaterra, 1995). Actes.Vol. 1. (J. Bosch, M. Molist, Orgs.) Rubricatum 1: 169-176.

JUAN-TRESSERRAS, J. y VILLABA, M.J. (1999): "Consumo de adormidera (Papaver somniferum L.) en el Neolítico Peninsular: el enterramiento M28 del complejo minero de Can Tintorer", II Congrés del Neolitic a la Península Ibèrica. SagvntuvmPlav, Extra-2: 397-404.

JUAN-TRESSERRAS, J. (2000): "La Arqueología de las Drogas en la Península Ibérica", Complutum 11: 261-274.

KNAPP, A. (1991): "Spices, Drugs, Grain and Grog: Organic Goods in Bronze Age East Mediterranean Trade", en N.H. Gale (ed.), Bronze Age Trade in the Mediterranean. Papers Presented at the Conference held at Rewley House, Oxford, December 1989, S.I.M.A., XC: 21-68. Jonsered: Paul Aströms.

MATA FUNES, M. (1946): "Exploración de la Gruta del Murciélago en Zuheros (Córdoba)", Boletín de la Real Academia de Córdoba 55: 125-130.

MARCOS POUS, A. (1977): "Posible edad neolítica de las pinturas rupestres esquemáticas de la Cueva de los Murciélagos (Zuheros)", Cordvba II: 111-118. Córdoba.

MARTÍ, B. y JUAN-CABANILLES, J. (2002): "La decoració de les ceràmiques neolítiques i la seva relació amb les pintures rupestres dels abrics de La Sarga", en La Sarga. Arte Rupestre y Territorio (M. Hernández y J.M. Segura, coords.). Ayuntamiento de Alcoy y Caja de Ahorros del Mediterráneo. 
MARTÍN, D. y CAMALICH, Ma .D. (1982): "La <Cerámica simbólica $>$ y su problemática (Aproximación a través de los materiales de la Colección L.Siret.", CPUGr. 7: 267-306. Granada.

MUÑZ, K (1998): El poblamiento desde el Neolítico Final a la Primera Edad del Hierro en la cuenca media del Tajo. Tesis Doctoral, inédita. Univ. Complutense. Madrid.

OLARIA, C. (1977): Las cuevas de los Botijos y la Zorrera en Benalmádena. Patronato Museo de Benalmádena. Málaga.

PELLICER, M. y ACOSTA, P. (1986): “Neolítico y Calcolítico de la Cueva de Nerja", en F.J. Jorda Pardo (ed.), La Prehistoria de la Cueva de Nerja (Málaga): 339-450. Patronato de la Cueva de Nerja, Málaga.

PEÑA-CHOCARRO, L. (1999): Prehistoric Agriculture in Southern Spain during the Neolithic and the Bronze Age. The application of ethnographic models. BAR Internacional Series, 818, Oxford.
RIVERA, D. y OBÓN DE CASTRO, C. (1991): Guía de Incafo de las Plantas Medicinales de las Península Ibérica y Baleares (Excluidas Medicinales). Incafo, S.A. Madrid.

ROJO, M. y KUNST, M., eds. (2002): Sobre el Significado del Fuego en los Rituales Funerarios del Neolítico. Studia Archaeologica 91. Valladolid.

SHERRAT, A. (1995): "Alcohol and its Alternatives: Symbol and substance in pre-industrial cultures", en Goodman y otros: 11-46.

VERA, J.C. y GAVILÁN, B. (1999): “Organización interna y usos del espacio en la Cueva de los Murciélagos de Zuheros (Córdoba)", Sagvntvm-Plav, Extra-2, Actes del II Congrés del Neolitic a la Península Ibèrica. (Valencia, 1999): 229-234.

VICENT, A.M ${ }^{\mathrm{a}}$. y MUÑOZ, A.M ${ }^{\mathrm{a}}$. (1973): Segunda campaña de excavaciones en la Cueva de los Murciélagos (Zuheros, Córdoba). E.A.E., 77. Madrid. 